\title{
Effect of Stratified Care for Low Back Pain in Family Practice (IMPaCT Back): A Prospective Population-Based Sequential Comparison
}

\author{
Nadine E. Foster, DPbil ${ }^{1}$ \\ Ricky Mullis, $P b D^{2}$ \\ Jonathan C. Hill, $P b D^{1}$ \\ Martyn Lewis, $P b D^{1}$ \\ David G. T. Whiteburst, $P b D^{3,4}$ \\ Carol Doyle, MSc ${ }^{1}$ \\ Kika Konstantinou, $P b D^{1}$ \\ Chris Main, $P b D^{1}$ \\ Simon Somerville, $M S c^{1}$ \\ Gail Sowden, MSc ${ }^{1}$ \\ Simon Wathall, HND ${ }^{1}$ \\ Julie Young, HND ${ }^{1}$ \\ Elaine M. Hay, $M D^{1}$ \\ on bebalf of the IMPaCT Back \\ Study team \\ 'Arthritis Research UK Primary Care \\ Centre, Keele University, Keele, Stafford- \\ shire, United Kingdom \\ ${ }^{2}$ The Primary Care Unit, Department of \\ Public Health \& Primary Care, University \\ of Cambridge, United Kingdom \\ ${ }^{3}$ Faculty of Health Sciences, Simon Fraser \\ University, Burnaby, British Columbia, \\ Canada \\ ${ }^{4}$ Centre for Clinical Epidemiology and \\ Evaluation, Vancouver Coastal Health \\ Research Institute, Vancouver, Canada
}

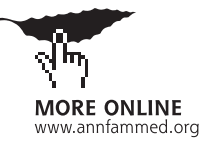

Conflicts of interest: authors report none.

\section{CORRESPONDING AUTHOR}

Nadine Foster, DPhil

NIHR Professor of Musculoskeletal Health in Primary Care

Arthritis Research UK Primary Care Centre

Primary Care Sciences

Keele University

Staffordshire ST5 5BG, United Kingdom

n.foster@keele.ac.uk

\begin{abstract}
PURPOSE We aimed to determine the effects of implementing risk-stratified care for low back pain in family practice on physician's clinical behavior, patient outcomes, and costs.
\end{abstract}

METHODS The IMPaCT Back Study (IMplementation to improve Patient Care through Targeted treatment) prospectively compared separate patient cohorts in a preintervention phase (6 months of usual care) and a postintervention phase (12 months of stratified care) in family practice, involving 64 family physicians and linked physical therapy services. A total of 1,647 adults with low back pain were invited to participate. Stratified care entailed use of a risk stratification tool to classify patients into groups at low, medium, or high risk for persistent disability and provision of risk-matched treatment. The primary outcome was 6-month change in disability as assessed with the Roland-Morris Disability Questionnaire. Process outcomes captured physician behavior change in risk-appropriate referral to physical therapy, diagnostic tests, medication prescriptions, and sickness certifications. A cost-utility analysis estimated incremental quality-adjusted life-years and back-related health care costs. Analysis was by intention to treat.

RESULTS The 922 patients studied (368 in the preintervention phase and 554 in the postintervention phase) had comparable baseline characteristics. At 6 months follow-up, stratified care had a small but significant benefit relative to usual care as seen from a mean difference in Roland-Morris Disability Questionnaire scores of $0.7(95 \% \mathrm{Cl}, 0.1-1.4)$, with a large, clinically important difference in the high risk group of 2.3 ( $95 \% \mathrm{Cl}, 0.8-3.9)$. Mean time off work was $50 \%$ shorter (4 vs 8 days, $P=.03$ ) and the proportion of patients given sickness certifications was $30 \%$ lower $(9 \%$ vs $15 \%, P=.03)$ in the postintervention cohort. Health care cost savings were also observed.

CONCLUSIONS Stratified care for back pain implemented in family practice leads to significant improvements in patient disability outcomes and a halving in time off work, without increasing health care costs. Wider implementation is recommended.

Ann Fam Med 2014;102-111. doi: 10.1370/afm.1625

\section{INTRODUCTION}

I has been stated that "most cases of back pain resolve regardless of the course of therapy, and some do not get better no matter what is done. Therein lies the problem for practitioners, patients, and policy makers." ${ }^{1}$ Health care systems universally face the challenge of providing effective primary care for low back pain within constrained resources, in the face of increased demands for treatment and investigations. ${ }^{2,3}$ Back pain is now the 6th highest contributor to the global burden of disease. ${ }^{4}$ In the United Kingdom, $6 \%$ to $9 \%$ of adults consult a family physician for back pain each year, ${ }^{5}$ accounting for $14 \%$ of consultations. ${ }^{6}$ More than $60 \%$ still report pain and disability a year later, ${ }^{7,8}$ and $2 \%$ to $7 \%$ will develop severe persistent symptoms ${ }^{9}$ leading to high levels of reconsultation, work loss, and sickness certification. ${ }^{10}$ Recent guidelines recommend 
evidence-based treatments, but the optimal approaches to target resources and improve the efficiency and effectiveness of primary care remain elusive. ${ }^{11}$

In response to internationally agreed-on research priorities, ${ }^{12}$ the recent Subgroups for Targeted Treatment (STarT) Back trial studied and demonstrated the clinical and cost-effectiveness of stratified care for nonspecific low back pain within physical therapy services in primary care. ${ }^{13,14}$ The trial compared stratified care-prognostic risk stratification into low, medium, and high risk groups combined with risk-matched treatment-with current best physical therapy practice and

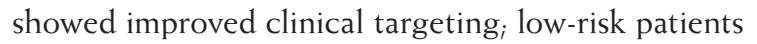
fared well with self-management, while medium- and high-risk patients were more often appropriately referred for physical therapy. To operationalize the trial and to ensure high levels of protocol compliance necessary to achieve high internal validity, patients consulting their family physician with nonspecific low back pain were referred to community-based, physical therapy-led clinics, which hosted the research. This approach contrasts with usual practice internationally, whereby first-contact care is most commonly provided by family physicians, and only a small proportion of patients (approximately 20\% in the United Kingdom) are referred to physical therapy. ${ }^{15}$ We therefore undertook the IMplementation to improve Patient Care through Targeted treatment (IMPaCT Back) study to address the unanswered questions of whether stratified care implemented within a primary care family physician setting is clinically effective, leads to more targeted use of health care resources by changing physician referral behavior, and reduces health care costs.

\section{METHODS}

\section{Design and Setting}

IMPaCT Back was a prospective, primary care-based, quality improvement study in England with a beforeand-after design. Full methods are reported in detail elsewhere. ${ }^{16}$ Sixty-four family physicians from 5 practices in a single health care region in Cheshire, England, participated. Each practice identified consecutive adult patients consulting their physician with low back pain during a usual care phase (phase 1: 6-month recruitment in 2008) and a stratified care phase (phase 3: 12-month recruitment in 2008-2009). Phase 2 was dedicated to the adoption of stratified care among participating practices and linked community-based physical therapists using a quality improvement package of training and support. Practices represented a range of characteristics including different settings (urban, semiurban, rural), practice sizes (ranging from 7-19 physicians and 9,75423,649 patients in their populations), models of access to physical therapy, and research experience (yes vs no). Practices were initially approached by members of the Primary Care Research Network in the West Midlands in the United Kingdom and recruited after an initial meeting with the research team at which the study was discussed. Five of 7 approached practices participated.

\section{Patient Sample}

Eligible adults (aged $\geq 18$ years) consulting with nonspecific low back pain of any episode duration, with or without associated leg pain, were identified using a standardized set of diagnostic Read codes. ${ }^{16,17}$ Read codes are the standard clinical terminology system used in general practice in the United Kingdom, identifying patients' clinical symptoms and diagnosis. An independent steering committee oversaw the study. Ethical approval was granted by the Cheshire Local National Health Service Research Ethics Committee (protocol 07/H1017/143).

\section{Phase 1: Usual Care}

For 6 months at each family practice (phase 1), we installed computer templates in Egton Medical Information (EMIS) systems that generated a message during the consultation when certain Read codes were entered. This message facilitated patient inclusion and exclusion, and prompted physicians to obtain initial consent for patients to receive study information. Contact details of consenting, eligible patients were obtained by weekly downloads. These patients were mailed study packets with an invitation letter, information leaflet, baseline questionnaire, and consent form (for follow-up and back-related medical record review). During this phase, family physician management involved assessment, advice, medication, sickness certification, and referral for investigations or further treatment as appropriate (eg, to community physical therapy or secondary care specialists), based on clinical judgment in negotiation with patients. Community-based physical therapists managed patients using clinical judgment to determine the number and content of treatment sessions. Importantly, we did not make any attempt to change usual care of low back pain patients in this phase, and clinicians were naive to the stratified care model to be implemented in the next phase of the study.

\section{Phase 2: Implementation}

During a 3-month period (phase 2), we introduced stratified care using a quality improvement program..$^{16,18}$ This evidence-based program for effecting clinician behavior change ${ }^{19,20}$ aimed to implement stratified care into the consultation by providing educational sessions, regular audit, peer feedback, and clinical mentoring opportunities. Details of the stratification tool and 
matched treatments for each risk stratum have been published. ${ }^{18,21,22}$ Briefly, the tool consists of 9 self-report items capturing 8 prognostic factors: function ( 2 items), radiating leg pain, pain elsewhere, depression, anxiety, fear avoidance, catastrophizing, and bothersomeness. The score ranges from 0 to 9 and allocates patients into 3 risk groups: low, medium, or high risk of persistent disability. For patients in the low-risk group, family physicians gave written information on self-management and advice to keep active, prescribed pain medications where appropriate, and reassured patients about their good prognosis. For patients in the medium-risk or high-risk group, physicians were encouraged to refer patients to physical therapy and address their backrelated concerns highlighted by the stratification tool.

We also trained 15 community-based physical therapists to stratify patients and provide risk-matched treatment. ${ }^{18,21,22}$ For patients categorized as low risk at the first physical therapy appointment, this approach involved a minimal package of assessment, education, and support for self-management, typically during a single session; for medium-risk patients, the physical therapy interventions focused on reducing pain and disability, increasing use of physical modalities (activity, exercise, and manual therapy), and encouraging patients in early return to work; for high-risk patients, psychologically informed physical therapy was provided. ${ }^{22}$ The informed physical therapy integrates simple cognitive-behavioral techniques with traditional physical therapy to reduce pain and disability, improve psychological functioning, and facilitate patients' confidence to self-manage future episodes. For all patients, physical therapists were encouraged to ask patients about their medication, counsel them about appropriate medication use, and liaise with family physicians with respect to those patients whose pain-relieving medication was insufficient to facilitate increases in physical activity.

\section{Phase 3: Stratified Care}

A new cohort of patients was recruited during a 12 -month period (phase 3 ) to assess the impact of stratified care, using identical processes to those in phase 1. Recruitment over this period enabled evaluation of the pattern of physician engagement in stratified care over time, measured at 3-month intervals by the extent to which physicians exited from the computer template pop-ups before completing the template, during back pain consultations. The computer template (pop-up) in phase 3 included a screen prompting physicians to complete the stratification tool in real time (ie, during the consultation) and provided a risk group-matched treatment recommendation. The same clinicians treated patients in phases 1 and 3. Contamination bias across phases was reduced by using identical study informa- tion packets and physician referral processes in both phases and ensuring that phase 1 participants reconsulting during phase 3 were not reinvited to participate.

\section{Outcomes}

To assess outcomes related to process of care, we captured physician clinical behavior pertaining to the targeting of health care resources by measuring numbers of referrals to physical therapy or other services, ordered diagnostic tests (radiographs, magnetic resonance imaging and computed tomography scans, blood tests), prescribed medications, reconsultations with the physician, and sickness certifications. These data were collected by research nurses from medical records for patients who gave consent. A key process outcome was risk-appropriate use of physical therapy (ie, nonreferral of patients at low risk and referral of patients at medium or high risk). Detailed data on physical therapy treatments were captured using case report forms for a sample of 40 patients each in phases 1 and 3 ( 80 patients in total).

To assess patient outcomes, we mailed patients self-report questionnaires at baseline (shortly after physician consultation) and at 2- and 6-month followups. The primary clinical outcome was change in back-related disability at 6 months assessed with the Roland-Morris Disability Questionnaire (RMDQ) ${ }^{23}$ on a scale of 0 to 24 , where higher scores indicate greater disability. Descriptions of the secondary outcome measures are reported in detail elsewhere ${ }^{16}$ but included back pain intensity, depression and anxiety, catastrophizing, fear avoidance beliefs, pain self-efficacy, healthrelated quality of life, global rating of change since baseline, risk group ascertained with the stratification tool, time off work, adverse events, and patient satisfaction. Research nurses overseeing minimum data collection ${ }^{16}$ could not be masked to study phase.

We assessed additional back pain-related use of health care resources with questions on the self-report questionnaire at 6 months, to be used in our economic evaluation. These data included inpatient stays, outpatient visits, other health care appointments including those in private practice, prescribed medication, and over-the-counter medications and treatments.

\section{Statistical Analysis}

Our primary analyses compared phase 1 (usual care) with phase 3 (stratified care) for the key process of care outcome (proportion of risk-appropriate referrals to physical therapy), the primary clinical outcome (backrelated disability measured by the RMDQ), and health care and societal cost-utility analyses. In secondary analyses, we tested for differences between study phases at the risk group level, which required a larger sample size than the primary analysis. Accordingly, the 
secondary analysis was used for the power calculation to test superiority of stratified care over usual care for patients at medium and high risk, and noninferiority for patients at low risk. Allowing for a $20 \%$ loss to follow-up, we aimed to recruit 1,000 participants to provide $80 \%$ power to detect a small overall treatment effect size of 0.2 , equivalent to a mean difference in RMDQ scores between phases of about 1.

Primary analysis was by intention to treat using imputed data sets (generated through multiple imputation by use of simulation based on a multivariate normal model). We obtained estimates of treatment effectmean difference for numerical outcomes, odds ratios for categorical outcomes, and incidence rate ratios for lost work days-with $95 \%$ confidence intervals by regression models adjusted for baseline score, age, sex, baseline RMDQ score, back pain duration, and physician practice. A $30 \%$ reduction in RMDQ score from baseline has been reported to be a minimal clinically important difference in this score for an individual patient. ${ }^{24}$ We therefore compared the proportion of patients achieving this difference in phases 1 and 3. Secondary analysis consisted of a per-protocol analysis comparing the subset of phase 3 patients who received risk-matched recommended treatment vs all phase 1 patients.

The cost-utility analysis focused on estimation of mean incremental quality-adjusted life-years (QALYs) and back-related health care costs (including National Health Service and private care) across phases 1 and 3. QALYs were generated from responses on the EQ-5D questionnaire, using United Kingdom-derived preference weights. ${ }^{25}$ Health care costs were estimated from self-reported resource use data at 6 months; the costs applied to units of resource use are reported in Supplemental Table 1. A sensitivity analysis explored productivity losses within phases 1 and 3. Costs were assigned to periods of back-related work absence using respondent-specific wage rate estimates identified from national data for yearly earnings and UK Standard Occupational Classification codes. ${ }^{26}$ In the economic analyses, no discounting was applied to costs or health benefits.

Further data collection and analyses specified in our protocol ${ }^{16}$ are reported in separate articles, for example, in-depth interviews eliciting physicians' and physical therapists' experiences of stratified care.

\section{RESULTS}

\section{Patient Characteristics}

A total of 922 patients were recruited: 368 in phase 1 and 554 in phase 3 . The 725 patients invited who did not respond to our baseline questionnaire were on average younger (44 vs 54 years) and more likely to be male $(50 \%$ vs $45 \%)$. Characteristics of the participating patients in each phase are shown in Table 1. In general, there was little difference in baseline demographic and clinical characteristics. Risk group proportions at baseTable 1. Baseline Characteristics of Potentially
Eligible and Participating Patients

\begin{tabular}{|c|c|c|}
\hline Characteristic & Phase 1 & Phase 3 \\
\hline \multicolumn{3}{|l|}{ Potentially eligible patients } \\
\hline Number invited (potentially eligible) & 630 & 1,017 \\
\hline Age, mean (SD), y & $47.9(16.8)$ & $49.2(15.8)$ \\
\hline Sex, female, No. (\%) & $340(54)$ & $570(56)$ \\
\hline Excluded, No. $(\%)^{a}$ & $28(4)$ & $47(5)$ \\
\hline Nonrespondents, No. (\%) & $234(37)$ & $416(41)$ \\
\hline Respondents, No. (\%) & $368(58)$ & $554(55)$ \\
\hline $\begin{array}{l}\text { Consented to medical record } \\
\text { review, No. (\%) }\end{array}$ & $307(83)$ & $421(76)$ \\
\hline Followed up at $2 \mathrm{mo}$, No. $(\%)^{\mathrm{b}}$ & $254(69)$ & $332(60)$ \\
\hline Followed up at 6 mo, No. $(\%)^{c}$ & $233(63)$ & $314(57)$ \\
\hline \multicolumn{3}{|l|}{ Participating patients } \\
\hline Age, mean (SD), y & $53.0(15.0)$ & $54.1(14.8)$ \\
\hline Sex, female, No. (\%) & $202(55)$ & $330(60)$ \\
\hline Routine/manual laborer, No. (\%) & $102(35)$ & $157(37)$ \\
\hline $\begin{array}{l}\text { Currently in paid employment, } \\
\text { No. (\%) }\end{array}$ & $227(62)$ & $323(59)$ \\
\hline $\begin{array}{l}\text { Time off work for back pain, No. } \\
(\%)^{\mathrm{e}}\end{array}$ & $109(49)$ & $133(42)$ \\
\hline Disability: RMDQ score, mean $(S D)^{f}$ & $8.7(5.9)$ & $8.4(5.7)$ \\
\hline Pain intensity: NRS rating, mean $(S D)^{g}$ & $5.3(2.4)$ & $5.0(2.6)$ \\
\hline \multicolumn{3}{|l|}{$\begin{array}{l}\text { Duration of back pain episode, } \\
\text { No. }(\%)\end{array}$} \\
\hline$<1$ month & $75(20)$ & $94(17)$ \\
\hline $1-3$ months & $62(17)$ & $102(18)$ \\
\hline 3-6 months & $75(20)$ & $111(20)$ \\
\hline 6 months to 3 years & $82(22)$ & $130(24)$ \\
\hline$>3$ years & $74(20)$ & $117(21)$ \\
\hline Leg pain, No. (\%) & $279(76)$ & $408(74)$ \\
\hline \multicolumn{3}{|l|}{ Risk group, No. (\%) } \\
\hline Low & $136(37)$ & $214(39)$ \\
\hline Medium & $151(41)$ & $232(42)$ \\
\hline High & $81(22)$ & $108(20)$ \\
\hline
\end{tabular}

$\overline{\text { NRS = numerical rating scale; } \mathrm{RMDQ}=\text { Roland-Morris Disability Questionnaire. }}$

axclusions: 8 patients in phase 1 and 23 patients in phase 3 had either died or moved primary care practice; 1 and 0 were unable to respond to questions; 11 and 19 did not want to participate; 6 and 4 did not have back pain; 1 and 0 had comorbid problems that were a priority; 1 and 1 were unable to take part.

${ }^{b}$ Losses to follow-up at 2 months: 102 patients in phase 1 and 217 patients in phase 3 did not respond to mailing; 9 and 0 had either died or moved primary care practice since baseline; 2 and 3 did not want to continue to take part; 0 and 1 did not have back pain; 1 and 1 had comorbid problems that were a priority. All baseline participants were retained for the purposes of intentionto-treat analysis (by imputation).

' Losses to follow-up at 6 months: 118 patients in phase 1 and 235 patients in phase 3 did not respond to mailing; 5 and 3 had either died or moved primary care practice since 2-month follow-up; 0 and 1 had comorbid problems that were a priority; 0 and 1 did not have back pain. All baseline participants were retained for the purposes of intention-to-treat analysis (by imputation).

${ }^{d}$ Based on major groups 5 to 9 of the UK Standard Occupation Classification (SOC, 2000) for current or most recent paid job.

e Respondents who were currently in paid employment at baseline and had time off in the 12 months before baseline.

f On a scale of 0 to $24: 0=$ no disability, 24 = maximum disability.

g On a scale of 0 to $10: 0=$ no pain, $10=$ pain as bad as could be. 
line were the same across both phases, with $38 \%$ at low risk, $42 \%$ at medium risk, and 20\% overall at high risk for persistent disabling symptoms.

\section{Process of Care Outcomes}

As shown in Table 2, implementation of stratified care led to significantly more risk-appropriate referrals to physical therapy for medium- and high-risk patients (40\% referred in phase 1 vs $72 \%$ referred in phase 3) but little difference for low-risk patients (65\% vs $68 \%$ not referred). In phase 3, physicians followed the stratification tool's recommendation for risk-matched treatment in 393 patients $(71 \%)$. The mean numbers of physical therapy treatment sessions provided in both phases were similar (3.8 vs 4.2 ), but physician reconsultations for back pain were more common in phase 3. Stratified care led to a significant more than $30 \%$ reduction in sickness certifications, as well as prescribing changes that included a decrease in use of nonopioids and a concurrent increase in use of mild opioids.

\section{Patient Clinical Outcomes}

The change in disability at 6 months was significantly better with stratified care than with usual care, with a mean difference between phases in RMDQ change of 0.7 (95\% CI, 0.1-1.4) (Table 3). Analyses of secondary outcomes showed significant benefits of stratified care in terms of fear avoidance beliefs, risk status, and patient satisfaction. Also, stratified care was associated with an overall $50 \%$ reduction in time off work. No adverse events were reported.

\section{Evaluation Within Risk Groups}

The benefit of stratified care on process outcomes was greatest for patients at high risk (evident in physician reconsultations and prescriptions) and medium risk (evident in prescriptions and sickness certification) (Table 4). Patients at high risk for poor outcome who were managed in phase 3 fared better in terms of disability, pain, and depression scores, with less work absence than those from phase 1 . Patients at medium risk had significantly better outcomes with respect to fear avoidance beliefs and less time off work due to back pain in phase 3 compared to phase 1 .

\section{Secondary Analyses}

Results at the 2-month follow-up are available from the authors; outcomes were similar for phase 1 and phase 3 . The per-protocol analyses (Supplemental Tables 2-4), which included all phase 1 patients and only those phase 3 patients for whom the physician followed stratified care, showed greater improvements in favor of stratified care compared with the intention-to-treat analysis.

\section{Economic Analyses}

Disaggregated mean health care costs are reported in Table 5, with total health care costs reported in Table 6. Disaggregated mean resource use is reported in Supplemental Table 5. Overall, stratified care was associated with a mean cost saving of $£ 34$ per patient and an incremental QALY estimate of 0.003 , with similar results observed in a complete-case analysis (cost saving $=£ 66$, incremental QALY=0.008). Supplemental Figure 1 graphically illustrates the uncertainty around the incremental cost and QALY point estimates. Regarding the indirect costs associated with back painrelated work absence, stratified care was associated with a mean savings of $£ 400$ per employed patient over 6 months (Table 5). 
Table 3. Patient Outcomes at 6-Month Follow-up

\begin{tabular}{|c|c|c|c|c|}
\hline Outcome & $\begin{array}{l}\text { Phase } 1 \\
(n=368)\end{array}$ & $\begin{array}{l}\text { Phase } 3 \\
(n=554)\end{array}$ & $\begin{array}{l}\text { Effect Estimate }^{a} \\
(95 \% \mathrm{CI})\end{array}$ & $\begin{array}{c}P \\
\text { Value }^{a}\end{array}$ \\
\hline \multicolumn{5}{|l|}{ Function and pain } \\
\hline $\begin{array}{l}\text { Disability: change in RMDQ } \\
\text { score }\end{array}$ & $2.2(6.0)$ & $2.7(5.5)$ & $0.71(0.06 \text { to } 1.36)^{b}$ & .03 \\
\hline Achieved MCIDc, No. (\%) & $154(42)$ & $261(47)$ & $1.24(0.92 \text { to } 1.67)^{d}$ & .15 \\
\hline $\begin{array}{l}\text { Pain intensity: change in } \\
\text { NRS rating }\end{array}$ & $1.7(2.8)$ & $1.9(3.2)$ & $0.29(-0.05 \text { to } 0.63)^{\mathrm{b}}$ & .09 \\
\hline $\begin{array}{l}\text { Physical function: change } \\
\text { in SF-12 PCS score }\end{array}$ & $-3.7(11.5)$ & $-3.9(16.3)$ & $-0.78(-2.47 \text { to } 0.92)^{b}$ & .35 \\
\hline \multicolumn{5}{|l|}{ Psychosocial outcomes } \\
\hline $\begin{array}{l}\text { Catastrophizing: change } \\
\text { in PCS-CAT score }\end{array}$ & $1.7(8.3)$ & $1.8(10.3)$ & $0.28(-1.13 \text { to } 1.68)^{b}$ & .67 \\
\hline $\begin{array}{l}\text { Fear avoidance: change } \\
\text { in TSK score }\end{array}$ & $2.5(8.3)$ & $3.6(11.2)$ & $1.58(0.53 \text { to } 2.62)^{b}$ & .006 \\
\hline $\begin{array}{l}\text { Anxiety: change in HADS } \\
\text { subscale score }\end{array}$ & $1.0(4 \cdot 4)$ & $1.2(4.7)$ & $0.34(-0.29 \text { to } 0.97)^{b}$ & .27 \\
\hline $\begin{array}{l}\text { Depression: change in } \\
\text { HADS subscale score }\end{array}$ & $1.0(4 \cdot 0)$ & $1.4(3.7)$ & $0.46(-0.07 \text { to } 0.98)^{b}$ & .08 \\
\hline $\begin{array}{l}\text { Mental health: change in } \\
\text { SF12 MCS score }\end{array}$ & $-1.9(14.3)$ & $-2.1(13.7)$ & $-0.56(-2.77 \text { to } 1.64)^{\mathrm{b}}$ & .58 \\
\hline $\begin{array}{l}\text { Pain self-efficacy: change } \\
\text { in PSEQ score }\end{array}$ & $-7.6(12.8)$ & $-7.2(15.5)$ & $-0.45(-2.16 \text { to } 1.26)^{b}$ & .60 \\
\hline \multicolumn{5}{|c|}{ Global change from baseline, No. (\%) } \\
\hline Completely recovered & $38(10)$ & $63(11)$ & $1.22(0.93 \text { to } 1.59)^{d}$ & .16 \\
\hline Much better & $102(28)$ & $178(32)$ & & \\
\hline Better & $88(24)$ & $129(23)$ & & \\
\hline No change & $95(26)$ & $127(23)$ & & \\
\hline Worse/much worse & $45(12)$ & $57(10)$ & & \\
\hline \multicolumn{5}{|l|}{ Risk group, No. (\%) } \\
\hline Low & $240(65)$ & $404(73)$ & $1.49(1.05 \text { to } 2.12)^{d}$ & .03 \\
\hline Medium & $96(26)$ & $122(22)$ & & \\
\hline High & $32(9)$ & $28(5)$ & & \\
\hline \multicolumn{5}{|l|}{ Work loss } \\
\hline $\begin{array}{l}\text { Absenteeism: days off work } \\
\text { since baseline }\end{array}$ & $7.9(23.5)$ & $4.3(14.5)$ & $0.47(0.24 \text { to } 0.92)^{f}$ & .03 \\
\hline $\begin{array}{l}\text { Presenteeism: reduced pro- } \\
\text { ductivity at work }\end{array}$ & $2.2(2.5)$ & $2.0(2.5)$ & $0.17(-0.42 \text { to } 0.75)^{b}$ & .57 \\
\hline \multicolumn{5}{|c|}{ Satisfaction with care received, No. (\%) ${ }^{g}$} \\
\hline Satisfied & $161(71)$ & $215(70)$ & $1.15(0.84 \text { to } 1.59)^{d}$ & .39 \\
\hline Neutral & $23(10)$ & $41(13)$ & & \\
\hline Not satisfied & $44(19)$ & $52(17)$ & & \\
\hline \multicolumn{5}{|c|}{ Satisfaction with results of care, No. $(\%)^{g}$} \\
\hline Very satisfied/satisfied & $133(59)$ & $209(70)$ & $1.50(1.04 \text { to } 2.16)^{d}$ & .03 \\
\hline Neutral & $39(17)$ & $45(15)$ & & \\
\hline Not satisfied & $52(23)$ & $46(15)$ & & \\
\hline
\end{tabular}

CSQ-CAT = Coping Strategies Questionnaire - CATastrophizing subscale; HADS = Hospital Anxiety and Depression Scale; $M C I D=$ minimal clinically important difference; MCS = Mental Component Subscale; PCS = Physical Component Subscale; PSEQ = Pain Self-Efficacy Questionnaire; RMDQ = Roland and Morris Disability Questionnaire; SF-12 $=$ Short Form 12; TSK $=$ Tampa Scale of Kinesiophobia

Note: Values are mean (SD) unless otherwise noted.

a Effect estimate and 95\% confidence interval derived by regression analyses adjusted for age, sex, general practice, baseline RMDQ, duration of pain, and corresponding baseline value.

${ }^{\mathrm{b}}$ Mean difference derived by linear regression.

" Based on an MCID ( $\geq 30 \%$ reduction in RMDQ score from baseline and rating of "completely recovered" or "much better" or "better" according to the global change question).

${ }^{d}$ Odds ratio derived by binary/ordinal logistic regression.

e Based on 290 of 547 respondents who reported being currently employed at 6 -month follow-up.

${ }^{\mathrm{f}}$ Incidence rate ratio derived by robust Poisson regression.

g Based on 536 respondents for the care received question and 524 for the results of care question at the 6 -month follow-up.

\section{DISCUSSION}

Compared with usual care, stratified care for patients with low back pain implemented in everyday family practice was associated with modest improvements in patients' outcomes overall, more targeted use of health care resources, and reduced sick certification without increased health care costs. Patient benefits included improvements in physical function, fear avoidance beliefs, satisfaction, and time off work. Significant changes to physician clinical behavior included increased numbers of riskappropriate referrals to physical therapy, reduced prescribing of nonsteroidal medications, and many fewer sickness certifications. Benefits from stratified care also included a concurrent small overall reduction in health care resource use and large societal cost savings due to fewer periods of painrelated work absence.

Our study was powered to compare outcomes within patient risk groups (low, medium, and high risk). Stratified care did not adversely affect pain or disability outcomes for patients at low risk of poor outcome. Physicians prescribed fewer nonsteroidal antiinflammatories and more weak opioid medications, and patients reported greater satisfaction with the results of care. Patients at medium risk received more physical therapy and more prescriptions for weak opioids, but fewer prescriptions for neuromodulator medications and far fewer sickness certificates. We did not include opioid prescription in the treatment protocols or clinician training packages; therefore, this increase in weak opioid prescription was unintended. Prescription of 
Table 4. Process of Care and Clinical Outcomes at 6-Month Follow-up by Risk Group

\begin{tabular}{|c|c|c|c|c|c|c|c|c|c|}
\hline \multirow[b]{2}{*}{ Outcome } & \multicolumn{3}{|c|}{ Low Risk } & \multicolumn{3}{|c|}{ Medium Risk } & \multicolumn{3}{|c|}{ High Risk } \\
\hline & $\begin{array}{l}\text { Phase } 1 \\
(n=136)\end{array}$ & $\begin{array}{l}\text { Phase } 3 \\
(n=214)\end{array}$ & $\begin{array}{c}P \\
\text { Value }^{\mathrm{a}}\end{array}$ & $\begin{array}{l}\text { Phase } 1 \\
(n=151)\end{array}$ & $\begin{array}{l}\text { Phase } 3 \\
(n=232)\end{array}$ & $\begin{array}{c}P \\
\text { Value }^{\mathrm{a}}\end{array}$ & $\begin{array}{l}\text { Phase } 1 \\
(\mathrm{n}=81)\end{array}$ & $\begin{array}{l}\text { Phase } 3 \\
(n=108)\end{array}$ & $\begin{array}{c}P \\
\text { Value }^{a}\end{array}$ \\
\hline \multicolumn{10}{|c|}{ Process of care outcomes } \\
\hline $\begin{array}{l}\text { Reconsulted physician, } \\
\text { No. (\%) }\end{array}$ & $19(18)$ & $33(22)$ & .43 & $39(31)$ & $74(41)$ & .056 & $30(42)$ & $52(58)$ & .03 \\
\hline \multicolumn{10}{|l|}{$\begin{array}{l}\text { Prescribed medica- } \\
\text { tions, No. (\%) }\end{array}$} \\
\hline $\begin{array}{l}\text { Nonsteroidal anti- } \\
\text { inflammatory drugs }\end{array}$ & $46(43)$ & $43(28)$ & .01 & $61(48)$ & $71(39)$ & .15 & $29(40)$ & $45(51)$ & .19 \\
\hline Antidepressants & $2(2)$ & $8(5)$ & .16 & $19(15)$ & $18(10)$ & .20 & $10(14)$ & $16(18)$ & .48 \\
\hline Nonopioids & $11(10)$ & $11(7)$ & .39 & $30(23)$ & $30(17)$ & .14 & $25(35)$ & $12(13)$ & .001 \\
\hline Opioids & $19(18)$ & $47(31)$ & .02 & $44(34)$ & $95(53)$ & .001 & $25(35)$ & $59(66)$ & $<.001$ \\
\hline Strong opioids & $12(11)$ & $25(16)$ & .24 & $37(29)$ & $49(27)$ & .75 & $24(33)$ & $40(45)$ & .13 \\
\hline Weak opioids & $7(7)$ & $22(14)$ & .046 & $7(5)$ & $46(26)$ & $<.001$ & $1(1)$ & $19(21)$ & $<.001$ \\
\hline $\begin{array}{l}\text { Neuromodulators/ } \\
\text { antiepileptics }\end{array}$ & $0(0)$ & $1(1)$ & 1.00 & $10(8)$ & $4(2)$ & .02 & $8(11)$ & $15(17)$ & .30 \\
\hline $\begin{array}{l}\text { Issued sickness certifi- } \\
\text { cation, No. (\%) }\end{array}$ & $10(9)$ & $11(7)$ & .54 & $21(16)$ & $16(9)$ & .046 & $14(20)$ & $13(15)$ & .41 \\
\hline $\begin{array}{l}\text { Blood test ordered, } \\
\text { No. }(\%)\end{array}$ & $33(31)$ & $50(33)$ & .73 & $46(36)$ & $65(36)$ & .98 & $31(43)$ & $39(44)$ & .92 \\
\hline $\begin{array}{l}\text { MRI scan/radiograph } \\
\text { ordered, No. (\%) }\end{array}$ & $12(11)$ & $10(7)$ & .19 & $20(16)$ & $29(16)$ & .91 & $15(21)$ & $16(18)$ & .65 \\
\hline \multicolumn{10}{|l|}{ Clinical outcomes } \\
\hline $\begin{array}{l}\text { Disability: change } \\
\text { in RMDQ score }\end{array}$ & $0.9(5.8)$ & $0.9(4.5)$ & .87 & $3.4(6.3)$ & $3.5(6.0)$ & .21 & $2.3(5.8)$ & $4.8(6.8)$ & .004 \\
\hline $\begin{array}{l}\text { Achieved MCID, } \\
\text { No. }(\%)\end{array}$ & $67(49)$ & $103(48)$ & .68 & $66(44)$ & $113(49)$ & .17 & $22(27)$ & $45(42)$ & .06 \\
\hline $\begin{array}{l}\text { Pain intensity: change } \\
\text { in NRS rating }\end{array}$ & $1.0(2.9)$ & $0.8(3.0)$ & .83 & $2.3(3.0)$ & $2.4(3.1)$ & .52 & $1.9(2.6)$ & $2.9(3.3)$ & .02 \\
\hline $\begin{array}{l}\text { Physical function: } \\
\text { change in SF-12 PCS } \\
\text { score }\end{array}$ & $-2.2(15.2)$ & $-2.6(16.5)$ & .98 & $-5.7(13.9)$ & $-4.0(11.9)$ & .79 & $-2.3(13.1)$ & $-6.1(14.8)$ & .051 \\
\hline $\begin{array}{l}\text { Catastophizing: change } \\
\text { in PCS-CAT score }\end{array}$ & $0.5(7.8)$ & $0.5(6.4)$ & .86 & $1.2(7.3)$ & $1.1(10.0)$ & .83 & $4.9(8.6)$ & $6.0(11.7)$ & .36 \\
\hline $\begin{array}{l}\text { Fear avoidance: change } \\
\text { in TSK score }\end{array}$ & $2.8(9.2)$ & $3.1(8.4)$ & .42 & $1.7(7.6)$ & $3.3(7.5)$ & .02 & $3.3(7.1)$ & $5.3(12.3)$ & .09 \\
\hline $\begin{array}{l}\text { Anxiety: change in } \\
\text { HADS subscale score }\end{array}$ & $0.7(4.1)$ & $0.6(4.2)$ & .82 & $0.8(3.7)$ & $1.0(4.0)$ & .09 & $2.1(5.5)$ & $2.7(4.3)$ & .22 \\
\hline $\begin{array}{l}\text { Depression: change in } \\
\text { HADS subscale score }\end{array}$ & $0.4(4.1)$ & $0.6(3.8)$ & .90 & $1.4(3.3)$ & $1.4(3.3)$ & .45 & $1.2(4.3)$ & $2.7(3.6)$ & .007 \\
\hline $\begin{array}{l}\text { Mental health: change } \\
\text { in SF-12 MCS score }\end{array}$ & $-1.1(13.4)$ & $-0.2(14.4)$ & .61 & $-1.2(13.8)$ & $-2.0(12.8)$ & .23 & $-4.8(17.4)$ & $-6.4(11.7)$ & .63 \\
\hline $\begin{array}{l}\text { Pain self-efficacy: } \\
\text { change in PSEQ score }\end{array}$ & $-4.9(13.7)$ & $-3.1(13.4)$ & .31 & $-9.6(16.8)$ & $-8.4(15.2)$ & .72 & $-8.4(12.5)$ & $-12.6(17.0)$ & .07 \\
\hline $\begin{array}{l}\text { Global change since } \\
\text { baseline: much } \\
\text { improved, No. (\%) }\end{array}$ & $67(49)$ & $116(54)$ & .48 & $53(35)$ & $88(38)$ & .11 & $19(24)$ & $41(38)$ & .09 \\
\hline $\begin{array}{l}\text { Risk group: low risk, } \\
\text { No. (\%) }\end{array}$ & $117(86)$ & $197(92)$ & .50 & $97(64)$ & $169(73)$ & .30 & $35(43)$ & $57(53)$ & .02 \\
\hline $\begin{array}{l}\text { Absenteeism since } \\
\text { baselinec }\end{array}$ & $0.5(2.3)$ & $0.9(3.4)$ & .50 & $11.3(26.3)$ & $5.3(18.7)$ & .005 & $15.5(35.5)$ & $9.4(16.8)$ & .41 \\
\hline Presenteeism ${ }^{c}$ & $1.5(2.0)$ & $1.2(1.5)$ & .32 & $2.3(2.3)$ & $2.3(2.8)$ & .87 & $3.7(3.1)$ & $3.2(2.8)$ & .62 \\
\hline $\begin{array}{l}\text { Satisfied with care } \\
\text { received }^{d}\end{array}$ & $59(75)$ & $81(76)$ & .87 & $77(75)$ & $99(70)$ & .39 & $25(54)$ & $35(59)$ & .61 \\
\hline $\begin{array}{l}\text { Satisfied with results } \\
\text { of care }^{d}\end{array}$ & $48(62)$ & $81(76)$ & .03 & $63(64)$ & $93(68)$ & .50 & $22(47)$ & $35(61)$ & .14 \\
\hline \multicolumn{10}{|c|}{ Notes: Values are mean (SD) unless otherwise noted. See Table 3 for abbreviations. } \\
\hline $\begin{array}{l}\text { a } P \text { values were derived by } \\
\text { RMDQ score, duration of pa } \\
\text { b Based on an MCID ( } \geq 30 \% \\
\text { question. } \\
\text { ' Based on } 290 \text { of } 547 \text { resp } \\
\text { d Based on } 536 \text { respondents }\end{array}$ & $\begin{array}{l}\text { test for the proce } \\
\text {, and correspond } \\
\text { duction in RMDC } \\
\text { dents who report } \\
\text { or the care receiv }\end{array}$ & $\begin{array}{l}\text { outcomes, and } \\
\text { g baseline value } \\
\text { score from basel } \\
\text { d being currentl } \\
\text { d question and } 5\end{array}$ & $\begin{array}{l}\text { regressior } \\
\text {-as detaile }\end{array}$ & $\begin{array}{l}\text { analyses for the } \\
\text { in Table 3). } \\
\text { of "completely } \\
\text { the 6-month fo }\end{array}$ & $\begin{array}{l}\text { linical outcomes } \\
\text { ecovered" or "mu } \\
\text { ow-up. }\end{array}$ & $\begin{array}{l}\text { adjusted for } \\
\text { ch better" o }\end{array}$ & $\begin{array}{l}\text { age, sex, family } \\
\text { "better" accorc }\end{array}$ & $\begin{array}{l}\text { physician practice } \\
\text { ing to the global }\end{array}$ & $\begin{array}{l}\text {, baseline } \\
\text { hange }\end{array}$ \\
\hline
\end{tabular}


Table 5. Costs of Back Pain-Related Health Care and Work Absence Per Patient

\begin{tabular}{|c|c|c|}
\hline \multirow[b]{2}{*}{ Health Care Resource } & \multicolumn{2}{|c|}{ Cost, Mean (SD), $\mathrm{E}$} \\
\hline & $\begin{array}{l}\text { Phase } 1 \\
(n=233)\end{array}$ & $\begin{array}{l}\text { Phase } 3 \\
(n=314)\end{array}$ \\
\hline \multicolumn{3}{|l|}{ Primary care contacts } \\
\hline Family physician: surgery & $36.82(53.5)$ & $32.38(50.1)$ \\
\hline Family physician: home visit & $0.45(6.9)$ & $2.04(20.5)$ \\
\hline Practice nurse: surgery & $1.51(6.2)$ & $0.80(3.8)$ \\
\hline Practice nurse: home visit & $0.09(1.3)$ & $0.06(1.1)$ \\
\hline \multicolumn{3}{|l|}{ Physiotherapy service } \\
\hline NHS & $33.15(60.8)$ & $45.09(77.2)$ \\
\hline Private health care & $13.82(63.7)$ & $11.90(40.8)$ \\
\hline \multicolumn{3}{|l|}{ Hospital-based care } \\
\hline NHS consultant & $33.64(84.5)$ & $29.95(80.7)$ \\
\hline NHS admissions & $9.79(91.6)$ & $12.84(116.9)$ \\
\hline NHS radiograph & $4.39(12.9)$ & $3.97(11.0)$ \\
\hline NHS CT scan & $0.43(6.6)$ & $1.32(11.2)$ \\
\hline NHS MRI scan & $16.90(55.0)$ & $17.38(53.9)$ \\
\hline NHS blood tests & $0.30(2.2)$ & $0.06(1.0)$ \\
\hline NHS epidural injections & $3.51(26.6)$ & 2.09 (19.9) \\
\hline Private consultant & $15.54(71.5)$ & $9.25(55.2)$ \\
\hline Private admissions & $4.97(75.8)$ & $3.68(65.3)$ \\
\hline Private diagnostic tests & $3.07(23.3)$ & $3.80(25.4)$ \\
\hline Private epidural injections & $0.88(13.4)$ & $0.02(0.1)$ \\
\hline \multicolumn{3}{|l|}{ Other health care professionals } \\
\hline NHS acupuncture & $2.44(17.5)$ & $1.83(20.6)$ \\
\hline NHS osteopathy & $0.16(2.5)$ & $3.19(20.8)$ \\
\hline NHS "other" & $8.52(46.7)$ & $4.96(33.9)$ \\
\hline Private acupuncture & $11.90(67.1)$ & $3.34(23.3)$ \\
\hline Private osteopathy & $11.08(37.0)$ & $9.02(38.7)$ \\
\hline Private "other" & $15.41(63.0)$ & $4.85(24.7)$ \\
\hline Out-of-pocket treatments ${ }^{\mathrm{a}}$ & $15.69(53.0)$ & $17.50(83.7)$ \\
\hline Prescribed medication ${ }^{a}$ & $17.32(80.1)$ & $6.56(19.5)$ \\
\hline $\begin{array}{l}\text { Work absence costs: time off } \\
\text { work due to low back pain }\end{array}$ & $758.75(2481.3)$ & 358.95 (1160.4) \\
\hline \multicolumn{3}{|c|}{$\begin{array}{l}\mathrm{CT}=\text { computed tomography; } \mathrm{MRI}=\text { magnetic resonance imaging; } \mathrm{NHS}=\text { National } \\
\text { Health Service. }\end{array}$} \\
\hline \multicolumn{3}{|c|}{$\begin{array}{l}\text { Notes: Analyses were among patients providing responses to the resource use questions at } \\
6 \text { months. Corresponding resource use data are reported in Supplemental Table } 5 .\end{array}$} \\
\hline \multicolumn{3}{|c|}{$\begin{array}{l}\text { Aggregate estimate that combines analgesics (nonopioid and weak opioid), nonsteroi- } \\
\text { dal anti-inflammatory drugs, gels, creams, sprays, aids, and appliances. }\end{array}$} \\
\hline \multicolumn{3}{|c|}{$\begin{array}{l}\mathrm{b} \text { The estimation of indirect costs focused on respondents in paid employment at } \\
6 \text {-month follow-up: } 132 \text { of } 229(58 \%) \text { in phase } 1 \text { and } 158 \text { of } 310(51 \%) \text { in phase } 3 .\end{array}$} \\
\hline
\end{tabular}

mild opioids is in line with back pain guidelines, however. ${ }^{11}$ Patients at medium risk also reported improved fear avoidance beliefs and significantly less time off work ( $>50 \%$ reduction). Patients at high risk, managed using stratified care, received more health care overall (physician consultations, referrals to physical therapy, and prescriptions for mild opioids); however, this greater use in turn led to significant improvements in disability and pain, depression, and time off work.

Improvements in the management of low back pain are needed ${ }_{1}^{27}$ yet changing behavior among family physicians is an identified challenge as clinicians struggle to have the time, skills, or inclination to translate evidence into practice to improve patient care. ${ }^{28}$ Physicians followed the screening tool's recommendation for matched treatment in $71 \%$ of cases, which remained stable over a 12 -month period. Stratified care's greatest impact on physician behavior was to reduce sickness certification (from 15\% to $9 \%$ ). Because of the high annual consultation rate for back pain among working-age adults $(6 \%),{ }^{5}$ this finding alone could result in substantial societal cost savings if family physicians routinely adopted stratified care. For example, an average saving of $£ 400$ per person consulting with back pain in the UK labor force of 29.17 million ${ }^{29}$ equates to an overall saving of more than $£ 700$ million ( $>\$ 1.1$ billion US).

IMPaCT Back is the first study to test the implementation of stratified care for low back pain within a primary care physician setting. The results extend the findings of the STarT Back trial. ${ }^{13,14}$ The mean difference in patient disability in IMPaCT Back was less than that in STarT Back, due in part to the higher proportion of low-risk patients in physician practice $38 \%$ vs $26 \%)$ and the variability in physician engagement with stratified care. Our per-protocol analysis demonstrated, however, that when patients were managed according to stratified care, absolute improvements in outcomes more closely repli-

Table 6. Total Back Pain-Related Health Care Costs in Different Analyses

\begin{tabular}{|c|c|c|c|c|}
\hline \multirow[b]{2}{*}{ Population } & \multicolumn{2}{|c|}{ Estimated Cost, Mean (SD), $€$} & \multirow{2}{*}{$\begin{array}{c}\text { Mean Difference } \\
(95 \% \mathrm{Cl}), \mathrm{€}\end{array}$} & \multirow[b]{2}{*}{$P$ Value } \\
\hline & Phase 1 & Phase 3 & & \\
\hline Intention-to-treat ( $\mathrm{N}=922)$ & $276.48(585.3)$ & $242.94(500.5)$ & $-33.54(-98.6$ to 31.5$)$ & .31 \\
\hline Complete resource use data ( $N=547)$ & $261.79(362.0)$ & $227.90(309.8)$ & $-33.89(-91.8$ to 24.0$)$ & .25 \\
\hline $\begin{array}{l}\text { Complete resource use and EQ-5D data } \\
(\mathrm{N}=447)\end{array}$ & $287.29(380.1)$ & $221.25(312.5)$ & $-66.04(-132.2$ to 0.2$)$ & .05 \\
\hline
\end{tabular}


cated the STarT Back trial. ${ }^{13}$ Previous implementation studies of back pain care have had mixed success but tend to conclude that multifaceted and active implementation strategies are of benefit. ${ }^{19,30}$ Results from our qualitative interviews with primary care physicians and physical therapists provide further information. ${ }^{31,32}$ Our quality improvement program, while aimed at primary care clinicians and teams, could be described as an integrated care organizational approach because it comprised various changes including revised professional roles, use of computer prompts and decision aids, and continued education. It remains to be seen whether physician-led stratified care will be encouraged in the same way it is for physical therapy services. For example, financial incentive initiatives, such as the UK Commissioning for Quality and Innovation payments, ${ }^{33}$ are rewarding physical therapy services to implement stratified care for back pain patients.

Although IMPaCT Back was not a randomized controlled trial, it has produced a reliable estimate of the effect of implementing stratified care for low back pain in physician practice. We opted for a pre-post design and not a cluster-randomized design because of contamination issues as 4 of the 5 participating general practices referred patients to physical therapists within the same health care region's physical therapy service. One limitation was our reliance on physicians to identify potentially eligible patients, which raises the possibility of selection bias; however, baseline data for both phases demonstrate such contamination did not occur and that our population was similar to that in previous UK primary care back pain studies. ${ }^{13,17,21}$ A second limitation was the differences in data sources used to determine patients' risk group in phase 1 (baseline questionnaires) and phase 3 (computer template completed in the physician consultation). There were limitations in selecting a 2-month follow-up time point, because most medium- and high-risk patients had not finished their physical therapy treatment at this point, as waiting times to first physical therapy appointments in both study phases averaged 4 to 6 weeks, similar to national averages. ${ }^{34}$ Finally, given the multiple objectives of this study, the problem of multiple testing and overall inflated type I error needs to be considered, although it is unlikely that we would obtain so many significant results if stratified care had no effect on outcomes.

In conclusion, our study shows that stratified care, in which prognostic screening is combined with matched treatment, is effective when implemented among physicians in primary care. It is associated with improved patient outcomes and reductions in work absence, without an increase in health care resource use. These results address guideline recommendations for further research on stratified care ${ }^{11}$ and have implications for future family physician practice. Stratified care is associated with benefits for patients and more targeted use of health care resource without increasing health care costs and should be implemented more widely.

To read or post commentaries in response to this article, see it online at http://www.annfammed.org/content/12/2/102.

Key words: low back pain; stratified care; subgroups; family practice; primary care; quality improvement; screening; practice-based research

Submitted June 4, 2013; submitted, revised, October 31, 2013; accepted December 14, 2013.

Funding support: The study was funded by the Health Foundation under its 'Engaging with Quality in Primary Care Programme' (grant code 346/4540) with support from the National Institute of Health Research (NIHR) Primary Care Research Network-North West, the Keele Academic General Practice Partnership, and the Primary Care Musculoskeletal Research Consortium. J.C.H. was supported through a fellowship from Arthritis Research UK. N.E.F. was supported in part by a National Coordinating Centre for Research Capacity Development (NCCRCD) Primary Care Career Scientist Award and is currently supported through an NIHR Research Professorship (NIHR-RP-011-015). K.K. was supported by a NIHR Clinical Lecturer award.

Disclaimer: The views expressed are those of the authors and not necessarily those of the NHS, the NIHR, or the Department of Health. None of the agencies that funded the study had any input into the study design, conduct, data collection, analysis or interpretation, reporting, or writing of this article.

Previous presentations: Foster NE, Mullis $R$, Lewis $M$, Whitehurst DGT, Hay EM on behalf of the IMPaCT Back study team. Implementation of targeted treatment for low back pain patients in primary care: a prospective population-based sequential comparison. North American Primary Care Research Group meeting, Dec 2012, New Orleans, Louisiana.

Foster NE, Mullis R, Doyle C, Lewis M, Whitehurst D, Hay EM. Implementation of subgrouping for targeted treatment for low back pain patients in primary care: a prospective population-based sequential comparison. International Forum for Low Back Pain Research in Primary Care, March 15-18, 2011, Melbourne, Australia.

Foster NE, Mullis R, Doyle C, Lewis M, Whitehurst D, Hay EM. Implementation of subgrouping for targeted treatment for low back pain patients in primary care: a prospective population-based sequential comparison. Annual European Congress of Rheumatology (EULAR), May 25-28, 2011, London, United Kingdom.

Foster NE, Mullis R, Doyle C, Lewis M, Whitehurst D, Hay EM. Implementation of subgrouping for targeted treatment for low back pain patients in primary care: a prospective population-based sequential comparison. Society of Academic Primary Care, July 6-8, 2011, Bristol, United Kingdom.

Foster NE, Mullis R, Doyle C, Lewis M, Whitehurst D, Hay EM. Implementation of subgrouping for targeted treatment for low back pain patients in primary care: a prospective population-based sequential comparison. Society of Back Pain Research, Nov 10-11, 2011, Cambridge, United Kingdom.

Acknowledgments: We thank the IMPaCT Back study independent steering group and clinical advisory group for their advice and support. We thank the general practice and physical therapy teams that participated in the study and particularly the clinicians who agreed to take on the role of link physicians in the practices and study leads in the physical therapy service. We thank patients for participating in the study. 
We are grateful to all the members of the wider IMPaCT Back study team: Tracy Whitehurst (health informatics); Paula Salmon (physical therapy), Meenee Khanna (clinical liaison); Majid Artus (PCP); June Handy (research nurse); Adele Higginbottom (research user); Stephanie Tooth, Tom Sanders, Bie Nio Ong (qualitative research); Jackie Gray (research governance and management); and Rhian Hughes (senior management and health partnerships). We also thank Prof Christian Mallen and Prof Kate Dunn for commenting on an early draft of the manuscript. Full information about the EMIS and paper-based versions of the stratification tool can be found at http://www.keele.ac.uk/sbst/.

Study registration: International Standard Randomised Controlled Trial Number ISRCTN55174281. http://www.controlled-trials.com/ ISRCTN55174281.

Supplementary material: Available at http://www.annfammed. org/content/12/2/102/suppl/DC1/

\section{References}

1. Shekelle PG, Delitto AM. Treating low back pain. Lancet. 2005;365 (9476):1987-1989.

2. Freburger JK, Carey TS, Holmes GM. Physical therapy for chronic low back pain in North Carolina: overuse, underuse, or misuse? Phys Ther. 2011:91(4):484-495.

3. Deyo RA, Mirza SK, Turner JA, Martin BI. Overtreating chronic back pain: time to back off? J Am Board Fam Med. 2009;22(1):62-68.

4. Vos T, Flaxman AD, Naghavi $M$, et al. Years lived with disability (YLDs) for 1160 sequelae of 289 diseases and injuries 1990-2010: a systematic analysis for the Global Burden of Disease Study 2010. Lancet. 2012;380(9859):2163-2196. Correction in Lancet. 2013;381(9867):628.

5. Dunn KM, Jordan K, Croft PR. Characterizing the course of low back pain: a latent class analysis. Am J Epidemiol. 2006;163(8):754-761.

6. Jordan KP, Kadam UT, Hayward R, Porcheret M, Young C, Croft P. Annual consultation prevalence of regional musculoskeletal problems in primary care: an observational study. BMC Musculoskelet Disord. 2010;11:144.

7. Croft PR, Macfarlane GJ, Papageorgiou AC, Thomas E, Silman AJ. Outcome of low back pain in general practice: a prospective study. BMJ. 1998;316(7141):1356-1359.

8. Itz CJ, Geurts JW, van Kleef M, Nelemans P. Clinical course of nonspecific low back pain: a systematic review of prospective cohort studies set in primary care. Eur J Pain. 2013;17(1):5-15.

9. McIntosh G, Hall H. Low back pain (acute). Clin Evid (Online). 2011; 1102-1132.

10. Wynne-Jones G, Mallen CD, Dunn KM. Sickness certification for musculoskeletal conditions. Clin Rheumatol. 2010;29(5):573-574.

11. Savingy $P$, Kuntze $S$, Watson $P$, et al. Low back pain: early management of persistent non-specific low back pain. London: National Institute of Clinical Evidence; 2009. http://www.nice.org.uk/CG88. Accessed Jun 4th, 2010.

12. Costa Lda C, Koes BW, Pransky G, Borkan J, Maher CG, Smeets RJ. Primary care research priorities in low back pain: an update. Spine. 2013;15;38(2):148-56.

13. Hill JC, Whitehurst DG, Lewis M, et al. Comparison of Stratified Primary Care Management for Low Back Pain With Current Best Practice (STarT Back): a randomised controlled trial. Lancet. 2011;378 (9802):1560-1571.

14. Whitehurst DG, Bryan S, Lewis M, Hill J, Hay EM. Exploring the cost-utility of stratified primary care management for low back pain compared with current best practice within risk-defined subgroups. Ann Rheum Dis. 2012;71(11):1796-1802.

15. Dunn KM. Epidemiology of low back pain in primary care: a cohort study of consulters [PhD thesis]. Staffordshire, United Kingdom: Keele University; 2004.
16. Foster NE, Mullis R, Young J, et al; IMPaCT Back Study team. IMPaCT Back study protocol. Implementation of subgrouping for targeted treatment systems for low back pain patients in primary care: a prospective population-based sequential comparison. BMC Musculoskelet Disord. 2010;11(11):186.

17. Dunn KM, Croft PR. Classification of low back pain in primary care: using "bothersomeness" to identify the most severe cases. Spine (Phila Pa 1976). 2005;30(16):1887-1892.

18. Sowden G, Hill JC, Konstantinou K, et al. IMPaCT Back study team. Targeted treatment in primary care for low back pain: the treatment system and clinical training programmes used in the IMPaCT Back study. Fam Pract. 2012;29(1):50-62.

19. Grimshaw JM, Thomas RE, MacLennan G, et al. Effectiveness and efficiency of guideline dissemination and implementation strategies. Health Technol Assess. 2004;8(6):iii-iv, 1-72.

20. Wensing M, Wollersheim H, Grol R. Organizational interventions to implement improvements in patient care: a structured review of reviews. Implement Sci. 2006;1:2.

21. Hill JC, Dunn K, Lewis M, et al. A primary care back pain screening tool: Identifying patient subgroups for initial treatment. Arthritis Care Res. 2008;59(5):632-641.

22. Main C, Hill J, Sowden G, Watson P. Integrating physical and psychosocial approaches to treatment in low back pain. The development and content of the Keele STarT Back trial's "high risk" intervention. Phys Ther. 2012;92(1):110-117.

23. Roland M, Morris R. A study of the natural history of back pain. Part I: development of a reliable and sensitive measure of disability in low-back pain. Spine (Phila Pa 1976). 1983;8(2):141-144.

24. Jordan K, Dunn KM, Lewis M, Croft P. A minimal clinically important difference was derived for the Roland-Morris Disability Questionnaire for low back pain. J Clin Epidemiol. 2006; 59):45-52.

25. Dolan P, Gudex C, Kind P, Williams A. The time trade-off method: results from a general population study. Health Econ. 1996;5(2): 141-154.

26. Annual survey of hours and earnings (ASHE). London: Office for National Statistics, 2008. http://www.ons.gov.uk/ons/guide-method/ surveys/list-of-surveys/survey.html?survey= Annual +Survey+of + Ho urs+and+Earnings+\%28ASHE\%29. Accessed Apr 14, 2010.

27. Mafi JN, McCarthy EP, Davis RB, Landon BE. Worsening trends in the management and treatment of back pain. JAMA Intern Med. 2013;173(17):1573-1581.

28. Ostelo R, Croft P, van der Weijden T, van Tulder M. Challenges in using evidence to inform your clinical practice in low back pain. Best Pract Res Clin Rheumatol. 2010;24(2):281-289.

29. Office of National Statistics 2011. Labour Market Statistics, September 2011. http://www.ons.gov.uk/ons/rel/lms/labour-marketstatistics/september-2011/statistical-bulletin.html. Accessed on Feb 28, 2013.

30. Bekkering GE, van Tulder MW, Hendriks EJ, et al. Implementation of clinical guidelines on physical therapy for patients with low back pain: randomized trial comparing patient outcomes after a standard and active implementation strategy. Phys Ther. 2005;85(6):544-555.

31. Sanders T, Foster NE, Bishop A, Ong BN. Biopsychosocial care and the physiotherapy encounter: physiotherapists' accounts of back pain consultations. BMC Musculoskelet Disord. 2013;14:65.

32. Sanders T, Foster NE, Ong BN. Perceptions of general practitioners towards the use of a new system for treating back pain: a qualitative interview study. BMC Med. 2011;9:49.

33. Commissioning for Quality and Innovation (CQUIN) Framework. http://www.institute.nhs.uk/world_class_commissioning/pct_portal/ cquin.html. Accessed Apr 18, 2013.

34. A survey of NHS physical therapy waiting times and musculoskeletal workload and caseload in England 2009-10. http://www.csp.org.uk/ publications/survey-nhs-physical therapy-waiting-times-musculoskeletal-workload-caseload-england-2009-1. Accessed Nov 30, 2012. 